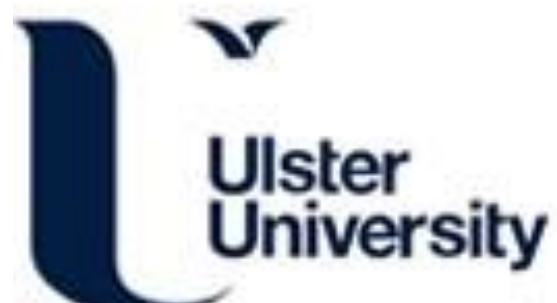

\section{Performance assessment of dry electrodes for wearable long term cardiac rhythm monitoring: skin-electrode impedance spectroscopy}

Bosnjak, A., Kennedy, A., Linares, P., Borges de Linares, M., McLaughlin, JAD., \& Escalona, OJ. (2017). Performance assessment of dry electrodes for wearable long term cardiac rhythm monitoring: skin-electrode impedance spectroscopy. In Unknown Host Publication (pp. 1861-1864). IEEE Xplore. https://doi.org/10.1109/EMBC.2017.8037209

Link to publication record in Ulster University Research Portal

\section{Published in:}

Unknown Host Publication

Publication Status:

Published (in print/issue): 14/09/2017

DOI:

10.1109/EMBC.2017.8037209

\section{Document Version}

Author Accepted version

\section{General rights}

Copyright for the publications made accessible via Ulster University's Research Portal is retained by the author(s) and / or other copyright owners and it is a condition of accessing these publications that users recognise and abide by the legal requirements associated with these rights.

\section{Take down policy}

The Research Portal is Ulster University's institutional repository that provides access to Ulster's research outputs. Every effort has been made to ensure that content in the Research Portal does not infringe any person's rights, or applicable UK laws. If you discover content in the Research Portal that you believe breaches copyright or violates any law, please contact pure-support@ulster.ac.uk. 


\title{
Performance assessment of dry electrodes for wearable long term cardiac rhythm monitoring: skin-electrode impedance spectroscopy*
}

\author{
Antonio Bosnjak, Alan Kennedy, Member, IEEE, Pedro Linares, Maira Borges, \\ James McLaughlin, Member, IEEE and Omar J. Escalona, Member, IEEE
}

\begin{abstract}
The use of wearable dry sensors for recording long term ECG signals is a requirement for certain studies of heart rhythm. Knowledge of the skin-electrode electrical performance of dry electrodes is necessary when seeking to improve various processing stages for signal quality enhancement. In this paper, methods for the assessment of dry skin-electrode impedance $\left(\mathrm{Z}_{\mathrm{SE}}\right)$ and its modelling are presented. Measurements were carried out on selected electrode materials such as silver, stainless steel, $\mathrm{AgCl}$ (dry) and polyurethane. These had $Z_{S E}$ values between $500 \mathrm{k} \Omega$ and $1 \mathrm{M} \Omega$ within the main ECG frequency range $(1 \mathrm{~Hz}-100 \mathrm{~Hz})$; in contrast to plain iron material which had a significantly higher impedance. However, in spite of the high $Z_{\mathrm{SE}}$ values, open bandwidth ECG traces were of acceptable quality and stability; with dry $\mathrm{AgCl}$ material offering the best ECG trace performance.
\end{abstract}

\section{INTRODUCTION}

Some patients need to be continuously monitored due to the nature of their specific condition. For example, a surgical procedure is sometimes used for long term rhythm monitoring and involves an implantable loop recorder. In this procedure, a device is positioned on the chest wall, under the skin, and the patient can be monitored for two years or longer. However, there are some inconvenient issues associated with this procedure, the device is expensive, and its use involves risks such as infection and aesthetic reactions among others [1]. Recently, a growing research interest has arisen in the area of wearable physiological measurement systems [2]. The development of devices that use highperformance electrodes for such demanding ambulatory applications remains a research challenge [3, 4].

Electrical activity of the heart is measured through the use of electrodes placed in specified locations on the patient's body. Signals recorded have several characteristic waves, namely, the $\mathrm{P}, \mathrm{Q}, \mathrm{R}, \mathrm{S}, \mathrm{T}$ and $\mathrm{U}$ waves. These waves contain important information concerning the heart's function. Amplitude and duration of the waves are among the aspects that have to be taken into account for diagnostic purposes [5]. An essential condition for good signal acquisition is a good electrical contact between skin and electrodes. In practice, electrodes can be broadly grouped into three different types, that is, wet (i.e. gelled), dry and capacitive coupled

*This research is supported by funding from the European Union (EU): H2020-MSCA-RISE Programme (WASTCArD Project, Grant \#645759).

A. Bosnjak, P. Linares and M. Borges are with the Universidad de Carabobo, Barbula, Edo. Carabobo, Venezuela.

A. Kennedy and J. McLaughlin are with the Ulster University, Newtownabbey, BT37 0QB, UK.

O. J. Escalona (corresponding author) is with the Ulster University, Newtownabbey, BT37 0QB, UK (Email: oj.escalona@ulster.ac.uk). electrodes. Wrist and arm locations for such monitoring systems are thought to be convenient for long term studies and dry sensors are considered advantageous, not requiring the re-gelling of electrodes. Dry electrodes do present higher skin impedances than gelled electrodes but can exhibit comparable performances with respect to motion artefacts under certain conditions [6].

An ideal electrode has a skin contact impedance close to zero and a contact potential equal to zero. This condition is not achievable in practice. A more realistic goal is to use electrodes that exhibit low skin-electrode impedances $\left(Z_{\mathrm{SE}}\right)$, and have similar properties from one electrode site to the next in an ECG recording. This study focuses on a method for the assessment, modelling and comparison of the $Z_{\mathrm{SE}}$ characteristics of different types of dry electrode materials over the main ECG signal frequency range of $1 \mathrm{~Hz}-100 \mathrm{~Hz}$ and broader bandwidth ranges.

\section{METHODS}

For the determination of the electrical impedance, a Schlumberger SI 1260 impedance/gain-phase analyser was used in combination with a biological sample interface SOLARTRON 1294 (Solartron 1260 and Solartron 1294, Solartron Analytical, Farnborough, UK). This impedance analyser set up constitutes a powerful and accurate combination typically used when experimental reliability is a requirement [7].

In figure 1, the experimental setup of the equipment and the positioning of the electrodes are shown. A "3-electrode" technique was used to characterise the electrode-skin impedance $\left(Z_{\mathrm{SE}}\right)$. Two standard pre-gelled $\mathrm{Ag} / \mathrm{AgCl}$ electrodes (Ambu, Blue Sensor SP-00-S) were placed on the forearm, one as a current return (bottom electrode), and the other as a reference electrode (top one). At $5 \mathrm{~cm}$ from this control electrode, the dry electrode under study was positioned, and to which the two positive cables from the SI 1260 were connected (yellow and black terminals).

This connection scheme measures the impedance of the electrode located within a constant test current $\left(\mathrm{I}_{\text {test }}\right)$ circuit path that includes: 1) the electrode to be evaluated (dry test electrode), 2) the interface between electrode and skin, 3) the epidermis, 4) The dermis and subcutaneous layers, and in the other extreme the circuit is closed by passing through 5) the dermis, 6) epidermis, 7) the gel and the electrode - skin interface of the return electrode [8]. Figure 1 illustrates the topology of the circuit elements involved in the connection scheme for the experimental impedance measurements.

The method for determining circuit parameters is represented by the block diagram shown in figure 2 . 
Measurements of impedance phase and magnitude, obtained with the impedance/gain-phase analyzer, were used as input to a curve fitting process. The goal was to fit, to experimental data, a polynomial function with coefficients derived from the circuit model. In order to test the implemented processor and method, discrete model circuits with known values of resistors and capacitors, were assembled and used as dummy impedances to obtain control measurements of impedance phase. In these test measurements on impedance dummies, parameters were calculated with error below $3 \%$ on average.

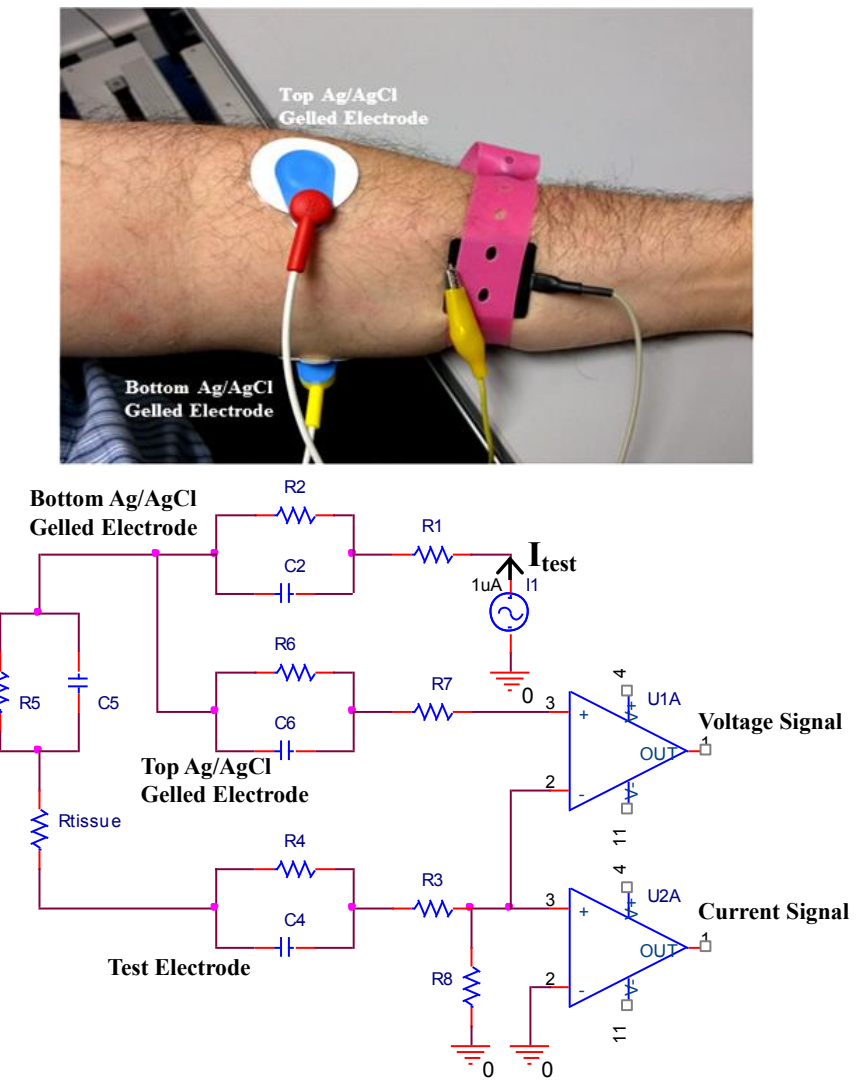

Figure 1. Experimental setup to measure the skin-electrode impedance.

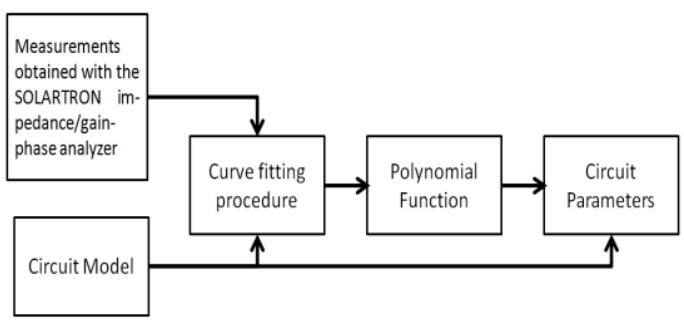

Figure 2. Curve fitting and estimation of circuit parameters block diagram.

To further describe the methodology, it would be useful to consider the underlying mathematical circuit model corresponding to the setup of the main electrodes used for impedance measurements in figure 1. This circuit model, among other things, would provide a means to verify that the measurements and the values obtained with computations from the model match well within the range of frequencies of interest. For verification purposes, four steps should be followed, namely, 1) perform the measurements with the impedance analyzer, 2) determine a circuit model for the set of interfaces of the electrodes and skin, 3) determine a detailed theoretical mathematical model for the circuit, and 4) simulate the circuit response with an appropriate tool such as Pspice - Orcad. The circuit can be simplified omitting the middle branch corresponding to $\mathrm{R}_{6} / / \mathrm{C}_{6}$, due to the fact that its current is null. Assambo et al. [9] proposed a circuit based on a double time constant model similar as shown in figure 3 .

The impedance function of the circuit is:

$$
\frac{V_{1}-V_{2}}{I_{1}}=\frac{R_{5}}{1+j \omega R_{5} C_{5}}+R_{\text {tissue }}+\frac{R_{4}}{1+j \omega R_{4} C_{4}}+R_{3}
$$

which can be simplified by defining the following resistor:

$$
R_{t 3}=R_{\text {tissue }}+R_{3}
$$

and the following time constants:

$$
\tau_{5}=R_{5} C_{5} \text { and } \tau_{4}=R_{4} C_{4}
$$

Once simplified using $R_{t 3}$ the impedance function magnitude can be expressed as:

$$
Z_{S E}=\frac{R_{5}\left(1+j \omega \tau_{4}\right)+R_{4}\left(1+j \omega \tau_{5}\right)+R_{t 3}\left(1+j \omega \tau_{4}\right)\left(1+j \omega \tau_{5}\right)}{1-\omega^{2} \tau_{5} \tau_{4}+j\left(\omega \tau_{4}+\omega \tau_{5}\right)}
$$

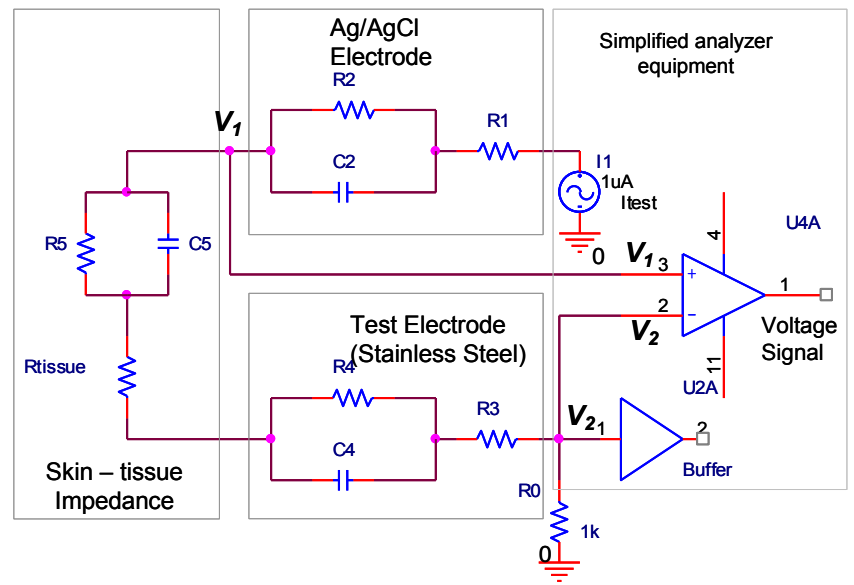

Figure 3. Schematic representation of the circuit setup for measurements assuming a double time constant model.

In the above expression for the transfer function, the phase angle is important because it can be used as a measure of model matching or how close are the experimental plot, output by the impedance analyser, and the analytical curve. Computing the arctangent from equation (4) the following relation can be obtained:

$$
\varphi(w)=\operatorname{Arg}\left(Z_{S E}\right)=\tan ^{-1}\left(\frac{\omega\left[R_{5} \tau_{5}+R_{4} \tau_{4}\right]+\omega^{3} \tau_{5} \tau_{4}\left[R_{4} \tau_{5}+R_{5} \tau_{4}\right]}{R_{T}+\omega^{2}\left[\tau_{4}^{2} R_{5 t}+\tau_{5}^{2} R_{4 t}\right]+\omega^{4} R_{t 3}\left(\tau_{5} \tau_{4}\right)^{2}}\right)
$$

Where:

$$
\begin{aligned}
& R_{4 t}=R_{4}+R_{t 3} \\
& R_{5 t}=R_{5}+R_{t 3} \\
& R_{T}=R_{4}+R_{5}+R_{t 3}
\end{aligned}
$$

Thus, these mathematical expressions provide a reference theoretical model, which can be useful for verification, as well as for designing the ECG front-end amplification stage or a required pre-signal processing stage.

A MATLAB program, aiming at the minimisation of the least squared error, was developed to adjust parameters of 
equation (5) to the data obtained experimentally with the Solartron analyser. This MATLAB coding is based on the lsqcurvefit function.

\section{RESULTS}

The setup described before was used with the purpose of performing measurements on five different types of dry electrodes that are sometimes used in electrocardiography and electroencephalography. The electrode materials used for the study are illustrated in figure 4. These are: 1) $\mathrm{AgCl}$ stud (Ringtrode, BQEL1); 2) Iron (Fe); 3) Polyurethane - multipin $-\mathrm{A}$; 4) Polyurethane - multipin -B; and 5) Silver disc (Ag).

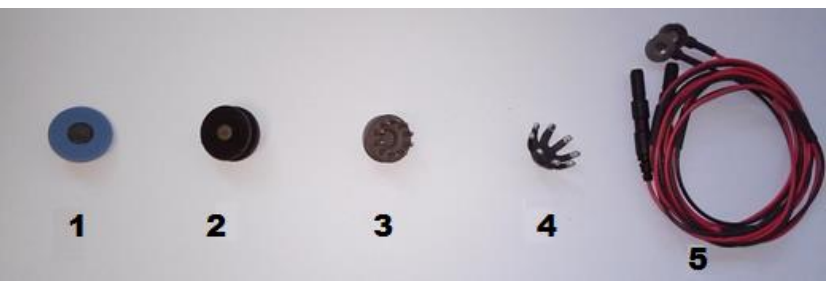

Figure 4. Dry electrodes used for the measurements: 1) $\mathrm{AgCl}$ stud, 2) Iron 3) Polyurethane multipin-A, 4) Polyurethane multipin-B, 5) Silver disc.

In an initial test, the impedance $Z_{\mathrm{SE}}$ for each electrode material was assessed applying them directly to the dry skin. The frequency was varied between $1 \mathrm{~Hz}$ and $750 \mathrm{kHz}$. The results obtained are shown in the graph of figure 5 .

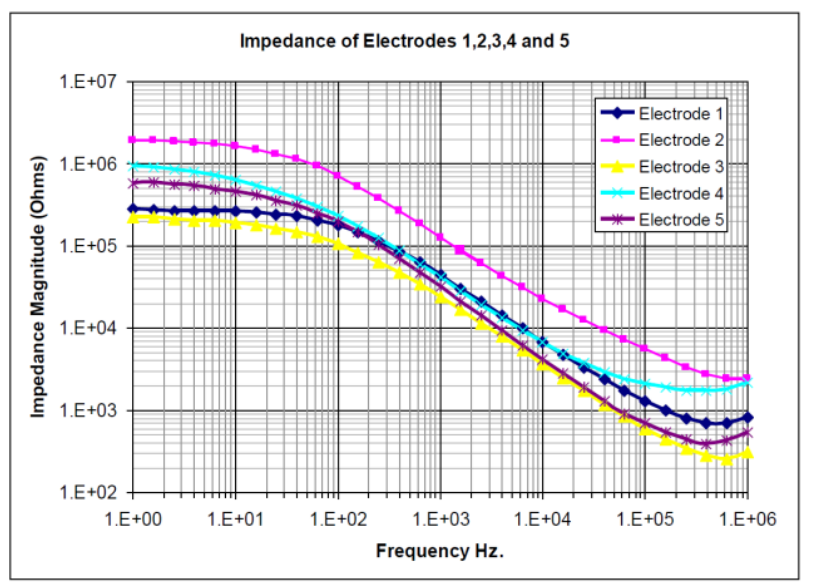

Figure 5. Impedance magnitude vs frequency for the 5 electrodes

It can be observed in this graph that electrode 3 , which is a multi-pin polyurethane-A electrode, has the lowest impedance at any frequency. This is perhaps because the pins get into better contact when pressed with the elastic band. This electrode is usually employed to acquire EEG signals. However, it can be unsuitable for long-term ECG recordings because it may prove uncomfortable to keep it in the arm for a long period of time.

In a separate test, a smooth-surface stainless steel electrode was used. One particular advantage of this electrode is that it seems to be comfortable enough to keep for a long time in the arm or forearm. In this test, as in the others, the impedance $Z_{\mathrm{SE}}$ with frequency was studied, but this time the electrode-skin area of contact was varied also. The graph in figure 6 shows this variation with area.
The graph shows how magnitude of impedance decreases with frequency as well as with growth in area, as expected. The SI 1260 impedance/gain-phase analyser also allows measuring the frequency response of the $R-R C$ circuit. The results of the measurements are stored in a CSV format that can be used for plotting the frequency response.
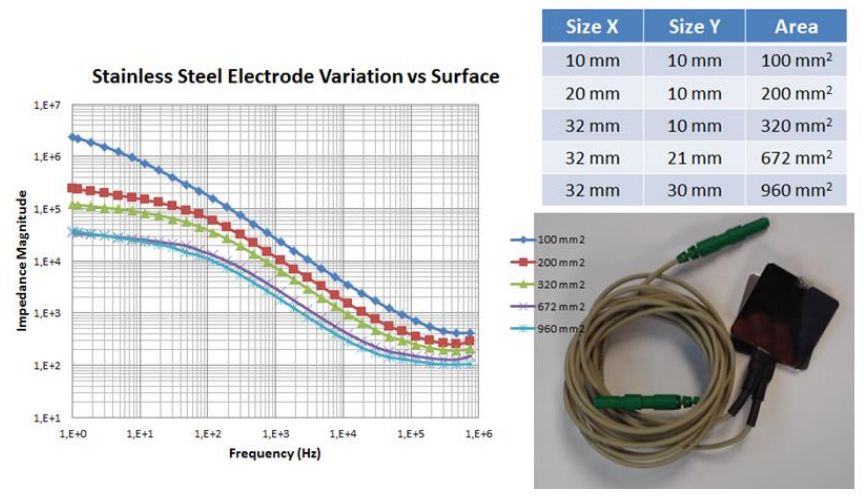

Figure 6. Stainless steel electrode impedance vs. frequency for different electrode-skin contact area.

Curve fitting tests were performed with measurements from electrodes shown in figure 4. An example of curve fitting for the polyurethane multipin-A dry electrode (\#3) is shown in figure 7 . There, a plot of the curve fitting using a one-time-constant model (red line), together with the adjustment for a double-time-constant model (blue line) are shown. The graph illustrates how, as expected, a circuit including a single discrete capacitor is less accurate in modelling the electrode under test and its $Z_{\mathrm{SE}}$ spectroscopy.

Once the minimization is achieved, the values for each of the resistors and capacitors in equations $(2-8)$ can be determined. These estimated values are presented in Table I.

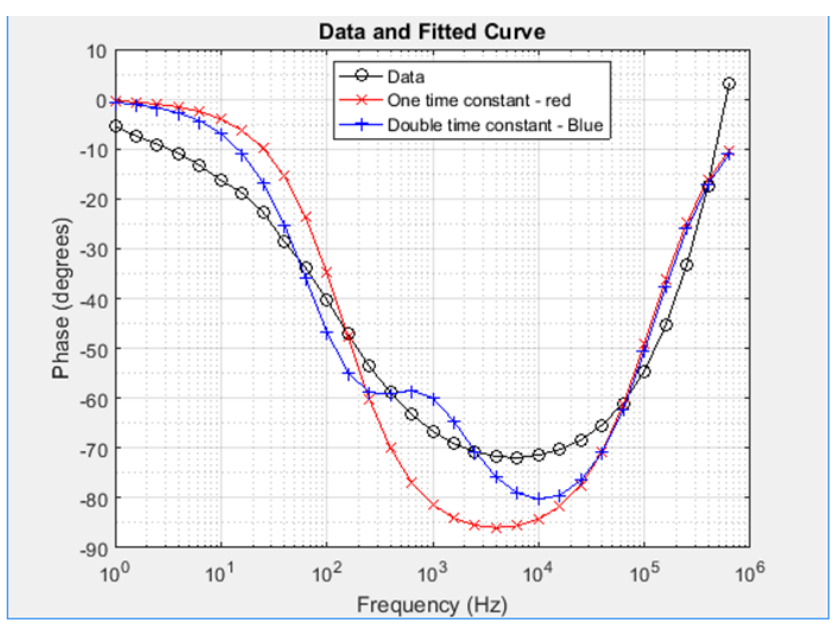

Figure 7. Curve fitting obtained for the phase frequency response. Experimental data ' $o$ '. One-time-constant model ' $x$ ' (red). Double-timeconstant ' + ' (Blue).

\section{OPEN BANDWIDTH ECG RECORDING TEST}

In order to assess the quality of cardiac ECG signals recording (Lead I) of the dry electrodes in this study (figure 4), using standard pre-gelled $\mathrm{Ag} / \mathrm{AgCl}$ electrodes as the standard for comparison, a multichannel ECG amplifier and 
Table I. Estimated values of circuit model parameters.

\begin{tabular}{|c|c|c|}
\hline Component & $\begin{array}{c}\text { Polyurethane }- \\
\text { multipin }-\boldsymbol{A}\end{array}$ & $\begin{array}{c}\text { Polyurethane }- \\
\text { multipin }-\boldsymbol{B}\end{array}$ \\
\hline $\mathrm{R}_{4}$ & $327.51 \mathrm{k} \Omega$ & $4.45 \mathrm{M} \Omega$ \\
\hline $\mathrm{C}_{4}$ & $6.43 \mathrm{nF}$ & $1.66 \mathrm{nF}$ \\
\hline $\mathrm{R}_{5}$ & $31.26 \mathrm{k} \Omega$ & $736.40 \mathrm{k} \Omega$ \\
\hline $\mathrm{C}_{5}$ & $3.69 \mathrm{nF}$ & $0.69 \mathrm{nF}$ \\
\hline $\mathrm{R}_{\mathrm{T}}$ & $359.32 \mathrm{k} \Omega$ & $5.20 \mathrm{M} \Omega$ \\
\hline $\mathrm{Rt}_{3}$ & $551.2 \Omega$ & $12.47 \mathrm{k} \Omega$ \\
\hline
\end{tabular}

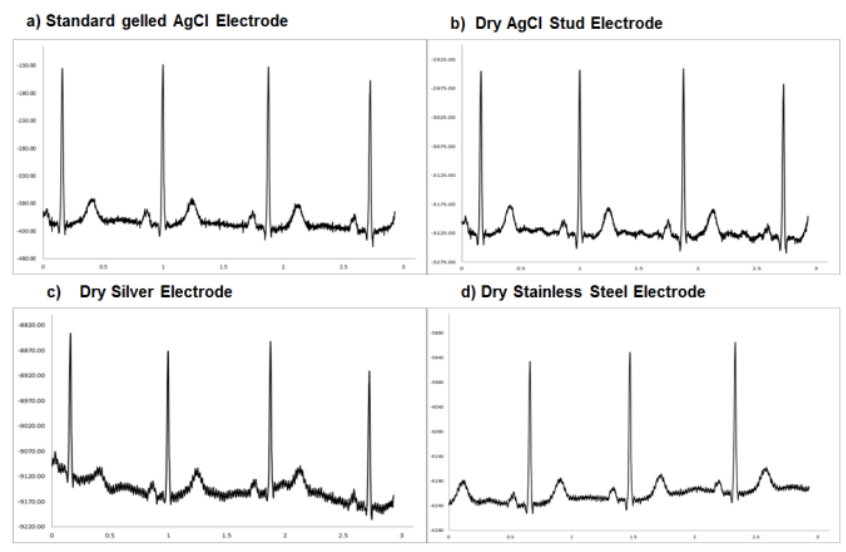

Figure 8. ECG Lead II recording quality (at open bandwidth, DC-1kH) with three dry electrode materials: (b) dry $\mathrm{AgCl}$ stud, (c) silver and (d) stainless steel, in comparison to standard gelled electrodes (a).

data acquisition system (BioSemi II), and which enabled DC- $1 \mathrm{kHz}$ bandwidth recordings, at 24-bit resolution and 2 $\mathrm{kHz}$ sampling rate, was used. In figure 8 , extracted best intervals of the recorded signals are illustrated.

It can be noted that, although background noise is present in all of the signals, information concerning the different waves can be identified in the gelled as well as in all dry electrodes, the most stable ECG trace presented by the dry $\mathrm{AgCl}$ stud electrodes.

\section{V.DISCUSSION}

In our proposed methods for assessing the feasible use of dry electrodes with selected materials, initial measurements were made using the circuit of figure 1 . The skin-electrode impedances spectra of 6 different dry electrodes were plotted in figures 5 and 6 , clearly revealing $Z_{\mathrm{SE}}$ values ranging between $500 \mathrm{k} \Omega$ and $1 \mathrm{M} \Omega$ within the main ECG frequency range $(1 \mathrm{~Hz}-100 \mathrm{~Hz})$, except for the contrasting case of iron $(\mathrm{Fe})$ material electrodes with $\mathrm{Z}_{\mathrm{SE}}$ values above $1 \mathrm{M} \Omega$. In figure 6 the area of skin contact of the stainless steel plate electrode was varied between $100 \mathrm{~mm}^{2}$ and $960 \mathrm{~mm}^{2}$; revealing a rather conservative $Z_{\mathrm{SE}}$ variation within the $500 \mathrm{k} \Omega-1 \mathrm{M} \Omega$ range, in the frequency range of interest as above. In this study, RC circuit models of double time constant were conveniently adopted and supported by the case results plots in figure 7 , in order to approximate the impedance function obtained with the Solartron equipment with the proposed circuit model in figure 3; with discrete parameters, resistances and capacitors, modelling the electrode material conductivity, the electrode-skin interface and the dermis-epidermis component, as presented in Table I for a particular dry electrode material with two different shapes. This modelling approach is useful for the proper design of the ECG amplifier circuit with a transfer function that would enable a more accurate cardiac ECG signal recording and reduce linear distortion. From this study, it can be appreciated from the case curve fitting graph in figure 7 , that the use of several polynomials can be adjusted to the phase response as a function of frequency, revealing that a 6 degree polynomial provided a reasonably phase response fit model for this particular application.

From the open bandwidth ECG recording tests, it is interesting to note that, in spite of the high $Z_{\mathrm{SE}}$ values measured with the selected dry electrode materials, the high resolution ECG traces (in the $0 \mathrm{~Hz}$ to $1 \mathrm{kHz}$ bandwidth) were of acceptable quality and stability; with the dry $\mathrm{AgCl}$ material offering the best ECG trace performance.

\section{CONCLUSION}

A setup for the performance assessment of the skinelectrode impedances, $Z_{\mathrm{SE}}$, has been implemented and used to assess a selected range of dry electrode materials. In overall, the behaviour of the dry electrodes used is encouraging for further comprehensive research, both in more adequate mathematical models and in-vivo metric based characterisation, followed by clinical studies on ECG traces using the selected dry electrode materials. This would enable better characterization of electrodes and their models for more adequate amplifiers design in wearable long term ECG monitoring systems.

\section{REFERENCES}

[1] W.D. Lynn , O.J. Escalona and D.J. McEneaney, "ECG monitoring techniques using advanced signal recovery and arm worn sensors". IEEE International Conference on Bioinformatics and Biomedicine, IEEE BIBM 2014 , pp. 51-55.

[2] O. Escalona and M. Mendoza, "Electrocardiographic Waveforms Fitness Check Device Technique for Sudden Cardiac Death Risk Screening". IEEE-EMBC 2016, Orlando, FL, pp. 3453-3456.

[3] T. Yilmaz, R. Foster and Y. Hao, "Detecting vital signs with wearable wireless sensors". Sensors. 10 (12), 2010, pp. 10837-10862

[4] Y.-H Chen, M.O. de Beeck, L. Vanderheyden, et al. "Soft, Comfortable Polymer Dry Electrodes for High Quality ECG and EEG Recording". in Sensors, Volume 14, 2014, pp. 23758-23780.

[5] P. K. Jain, A. K. Tiwari, "Heart monitoring systems - A review," in Computers in Biology and Medicine, Volume 54, 2014, pp. 1-13.

[6] A. Searle and L. Kirkup," "A direct comparison of wet, dry and insulating bioelectric recording electrodes." in Physiological Measurement, Volume 21, 2000, pp. 271-283.

[7] J. Strand-Amundsen, C. Tronstad, H. Kalvøy, et al. "In vivo characterization of ischemic small intestine using bioimpedance measurements". Physiological Measurement, vol. 37, Issue 2, pp. 257-275. January 2016

[8] E. McAdams, "Bioelectrodes". Encyclopedia of Medical Devices and Instrumentation, Second Edition, edited by John G. Webster. Copyright (C) 2006 John Wiley \& Sons, Inc. pp. $120-166$.

[9] C. Assambo, R. Dozio, A. Baba and M. J. Burke "Determination of the Parameters of the Skin Electrode Impedance Model for ECG Measurement". Proc. 6th Int. Conf. on Electronics, Hardware, Wireless and Optical Communications, February 2007, pp. 540-318. 